\title{
Avaliação da cicatrização induzida pela membrana de celulose porosa depois da retirada total da pele em dorso de ratos
}

\author{
Assessment of induced healing by porous cellulose \\ membrane after complete removal of a skin \\ segment from the back of rats
}

Nelson Yaguishita*

\section{Resumo}

Introdução: Existem, atualmente, mais de 2.000 tipos de curativos disponíveis no mercado internacional destinados a feridas e queimaduras, o que provoca inúmeras dúvidas a respeito da melhor indicação terapêutica.

Objetivo: Analisar os efeitos da cicatrização induzida pela membrana de celulose porosa depois da retirada total da pele do dorso de ratos.
\end{abstract}

Método: Este trabalho foi aprovado pelo Comitê de Ética em pesquisa da Sociedade Evangélica Beneficente

\footnotetext{
* Membro efetivo, SBACV.
}

Conflito de interesse: Nelson Yaguishita recebeu bolsa de Mestrado da CAPES durante a realização deste trabalho. Não tem participação societária nem recebeu auxílios da empresa fabricante.

Trabalho realizado no Instituto de Pesquisas Médicas (IPEM) do Programa de Pós-Graduação em Princípios de Cirurgia da Faculdade Evangélica do Paraná (FEPAR) e Hospital Universitário Evangélico de Curitiba (HUEC). Dissertação aprovada como requisito parcial para obtenção do grau de Mestre.

Orientador: Prof. Dr. Jurandir Marcondes Ribas Filho

Co-orientadora: Profa. Dra. Célia Toshie Yamamoto

Apresentação: 09/08/2006

Banca examinadora: Prof. Dr. Henrique Jorge Stahlke Júnior (UFPR), Prof. Dr. José Fernando Macedo (FEPAR), Prof. Dr. Hamilton Moreira (FEPAR e UFPR).

Artigo submetido em 22.04.07, aceito em 10.05.07.

J Vasc Bras 2007;6(2):193-194.

Copyright $\odot 2007$ by Sociedade Brasileira de Angiologia e de Cirurgia Vascular de Curitiba. Foram estudados 40 ratos (Rattus norvegicus) da raça Wistar, distribuídos aleatoriamente da seguinte maneira: 20 animais no grupo controle (GC) e 20 animais no grupo membrana (GM). Na região anatômica padronizada, foi ressecado um segmento total de pele, utilizando-se um molde de silicone de quatro $\mathrm{cm}$ de diâmetro e um bisturi de lâmina, expondo-se a face muscular dorsal. Após o ato operatório, foi aplicado curativo com gaze seca (GC) ou uma Membracel ${ }^{\circledR}$, desidratada e estéril (GM). Os animais foram mortos no $7^{\circ}, 14^{\circ}, 21^{\circ}$ e $28^{\circ}$ dias do pós-operatório (DPO). Para tanto, cinco animais do GM e cinco do GC foram colocados sob campânula, e mortos por meio de overdose inalatória de éter etílico. Na macroscopia, foram estudados o fundo e a área da lesão, sendo que para a avaliação do fundo do ferimento utilizou-se a classificação pelo sistema de cores da seguinte maneira: vermelha, amarela e preta. Para a medida da área da ferida, foi utilizada a planimetria digital. Já na microscopia, a epitelização foi qualificada após coloração de hematoxilina eosina e a colagenização após a coloração de picrosirius. Definiu-se previamente um valor de significância quando $\mathrm{p}<0,05$.

Resultados: A análise comparativa entre os animais do GM com os do GC revelou que no GM o fundo da ferida apresentou predominância da coloração vermelha a partir do $14^{\circ} \mathrm{DPO}(\mathrm{n}=10 \mathrm{GM}=40 \% \mathrm{e} \mathrm{GC}=0 \%$; $\mathrm{p}=0,0476)$ e área de ferida aberta com diminuição 
significante a partir do $21^{\circ} \mathrm{DPO}(\mathrm{GM}=12,71 \% \pm 4,69 \mathrm{e}$ $\mathrm{GC}=24,67 \% \pm 7,22 ; \mathrm{p}=0,0317)$. A reepitelização completa $(\mathrm{n}=10 \mathrm{GM}=50 \%$ e GC $=10 \% ; \mathrm{p}=0,0476)$ e a deposição de colágeno maduro $(n=10 \mathrm{GM}=50 \% \mathrm{e}$ $\mathrm{GC}=10 \% ; \mathrm{p}=0,0476$ ) foram observadas a partir do $14^{\circ}$ DPO para ambas variáveis.
Conclusão: Neste experimento, o uso da membrana de celulose porosa favoreceu a cicatrização em ferimento de pele total na região dorsal de ratos.

Palavras-chave: Membrana de celulose porosa, cor da ferida, área de lesão, reepitelização, colágeno, ratos. 